\title{
Research of Material Concepts on Arts Education
}

\author{
Bing Liu \\ Academy of Fine Arts \\ Northeast Normal University \\ Changchun, CHINA \\ ice8515@163.com \\ Fu Liu \\ Academy of Fine Arts \\ Northeast Normal University \\ Changchun, CHINA \\ Fuliu6286@163.com
}

\author{
Fan Wang * \\ Academy of Fine Arts \\ Northeast Normal University \\ Changchun, CHINA \\ Wangf06@163.com \\ Hongtao Zhou \\ School of Architecture \\ University of Hawai'i at Manoa \\ HI, USA \\ lifeisfurniture@gmail.com
}

\begin{abstract}
Materials changes interpretation of the art updates, the replacing of the idea determines the language value and significance of the material in art, in modern art education, knowledge of the material not only in the understanding of its surface texture, outer shape of emotional experience, more importantly, its artistic language based art education from the outside to the inside of the extension. In art education to guide students to explore new materials and forms of artistic expression, recognizing its aesthetic expression when the subject has a wealth of potential, deepening reform and artistic innovation, with global vision to select and educational knowledge, arts education will get new interpretation.
\end{abstract}

Keywords-Arts Education; Material; Concept of innovation; Orientation and change

\section{INTRODUCTION}

From the West in the early rock paintings to paper pencil, pen drawing, pastels, from the wall to the egg tempera on canvas, watercolor, encaustic, painting, and then to the early 20th Century emerging acrylic painting; from China's silk painting, lacquer painting to painting appeared in succession; from the simple use of easel painting to painting materials using a variety of domestic, industrial materials and even the human body to create installation art, land art and performance art, we can clearly see: each new art materials are discoveries, inventions and applications, means a new artistic language was created and applications, means the improvement of human artistic creativity, people know every art materials deepening, means people about art materials the original concept of change[1]. People in the new material concepts dominate, using new or old materials to create artistic language different from the past, causing a series of changes artistic visual image, make new artistic styles and genres to be born [2].

In the contemporary art education, people started understanding of art materials from outside to inside the deepening and language skills of the art materials constantly digging. Ordinary materials into a new artistic language, however, when this material is used by artists and other material into another artistic background or context, it becomes

Corresponding author: Fan WANG, Wangf06@163.com, Professor, Northeast Normal University, CHINA. Hongtao Zhou, lifeisfurniture@gmail.com,Assistant professor, University of Hawai'i at Manoa, USA. a language, this language because of its unique context and has its own persuasive and expressive, rational thinking makes people think directly what is not art, but rather to consider the true meaning of life. Thus, at this point the art materials from "endorsement" to "self-made", it has been transformed into a non-realistic "objects", and this non-reality of the "objects" pointing sociological aspects of spiritual inclinations, with a profound spirit of practical relevance requirements [3].

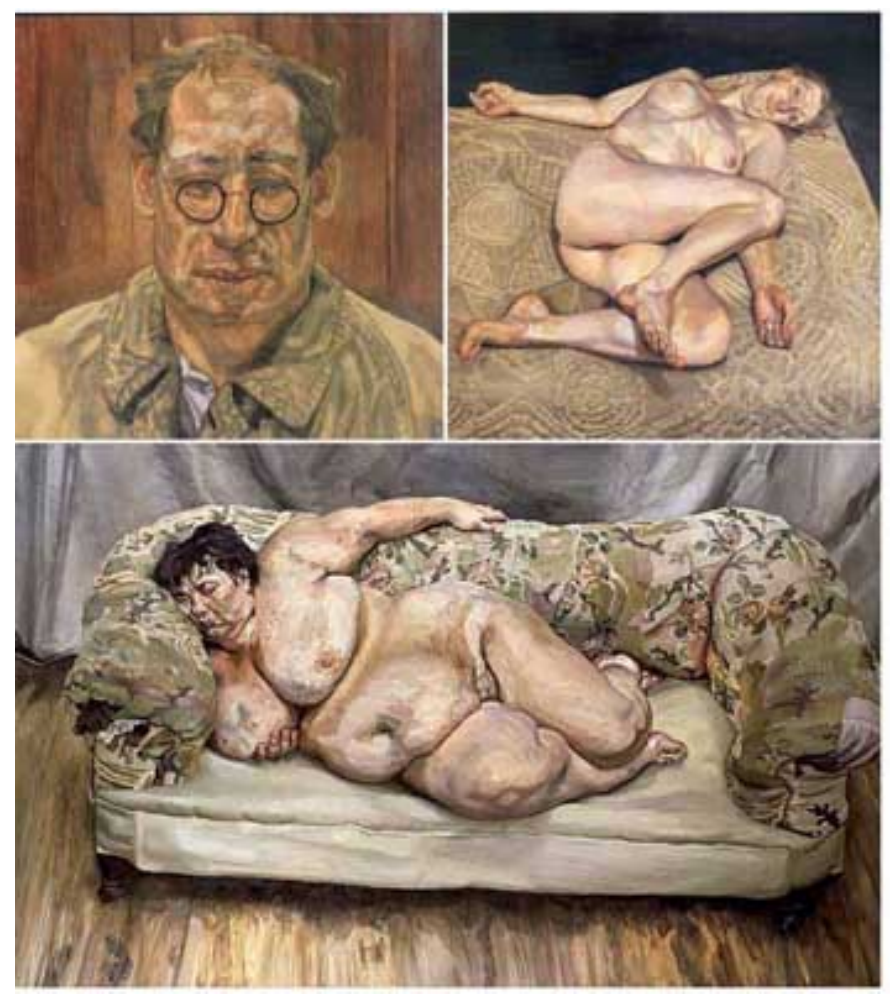

Fig. 1. The Works of Lucian Freud

\section{FROM SURFACE TO APPEARANCE}

Any work of art, must rely on some material medium can be realized, however, in most cases, traditionally, we are used 
to from the material point of view is divided into different kinds of art, however, in traditional Chinese painting, oil painting, printmaking, sculpture and other art forms, often only using single fixed material, dependence skill of painted, painted, carved, and other techniques to copy reproduction otherness. Material as a tool for shaping the artistic image of the media, when art image-building to complete, end of artistic creation, the material often relegated to the background, ablation in the image into a new art, at this time people pay more attention material in its natural form, focus on physical properties desirable texture and texture.

Texture is an important oil painting language, excellent painter in the use of brush strokes, always on top of the canvas showing different texture characteristics. Lucian Freud (19222011), the world's most iconic realist painter, we look at the works of Freud will find in each period, strokes of his work has always maintained a strong unique style, in his work, especially in the human body, strokes with space, volume, texture, light and shadow, color and other factors to obtain a unified painting, strokes with space, volume, texture, light and shadow, color and other factors, to achieve uniform, the formation of a unique appearance with aesthetic value picture language, as shown in Figure 1. Lucian Freud borrowed strokes, texture images, the texture of the language of painting, figurative painting in the field of application developed to irrefutable realm, also makes the painting material "The abstract language of figurative painting in the field of application extended to a broader level, while the language itself also received strong vitality. "

With the rise and development of industrial civilization, technological advances not only broadens the human understanding of the economic life of the material field, have deepened humanity from materials application technology and external forms of research, and gradually turned to the study material cultural significance, this level of material in modern and contemporary art language integrated physical installation art was particularly prominent.

"Neo-expressionist" artist Anselm Kiefer (1945- ) inherited the Joseph Beuys (1921-1986) concept of social sculpture, make full use of various materials in the form of language to express the theme, including the use of paint, clay, lead, stone, models, photographs, prints, straw, shellac and various organic materials, through the re-integration of these ready-made materials, ready-made materials retained symbolic nature as shown in Figure 2. More and more new materials in new forms and new manifestations methods began to be widely used, obtain multiple interpretations. Modern art and the latter part of the post-modern art genre surging, artistic genres, and styles everywhere, all of this is a new concept, the deconstruction of artistic language system on the material presented in the best proof.

\section{EMOTIONAL STANDING ACROSS BORDERS}

Early modern art movement of materials that have intrinsic conceptual, reflected in the architectural design. Adolf Loos

(1870-1933) advocated building a practical and comfortbased, made his famous "decoration is evil" slogan, Adolf Loos advocated building a practical and comfort-based, made his famous "decoration is evil" slogan, and that the construction "Rather than relying on its own body decoration is art", representative works was built Vienna Steiner House, 1910 and in Prague designed house built Miller, 1930. His architecture is characterized by its own characteristics using different materials for construction, focus on building a cube combination, and the ratio between the walls and windows, in the selection of materials, carefully selected, processing of materials, attention to material's natural texture, as L.B. Leon Battista Alberti (1404-1472), he often uses with abstract pattern textured surface materials, and willing to intrinsic properties of the material through the performance to excite the imagination of the user. For example, in interior design, wood, textured marble, mirrors, leather, fabrics and carpets and other materials are combined together to create a warm atmosphere.

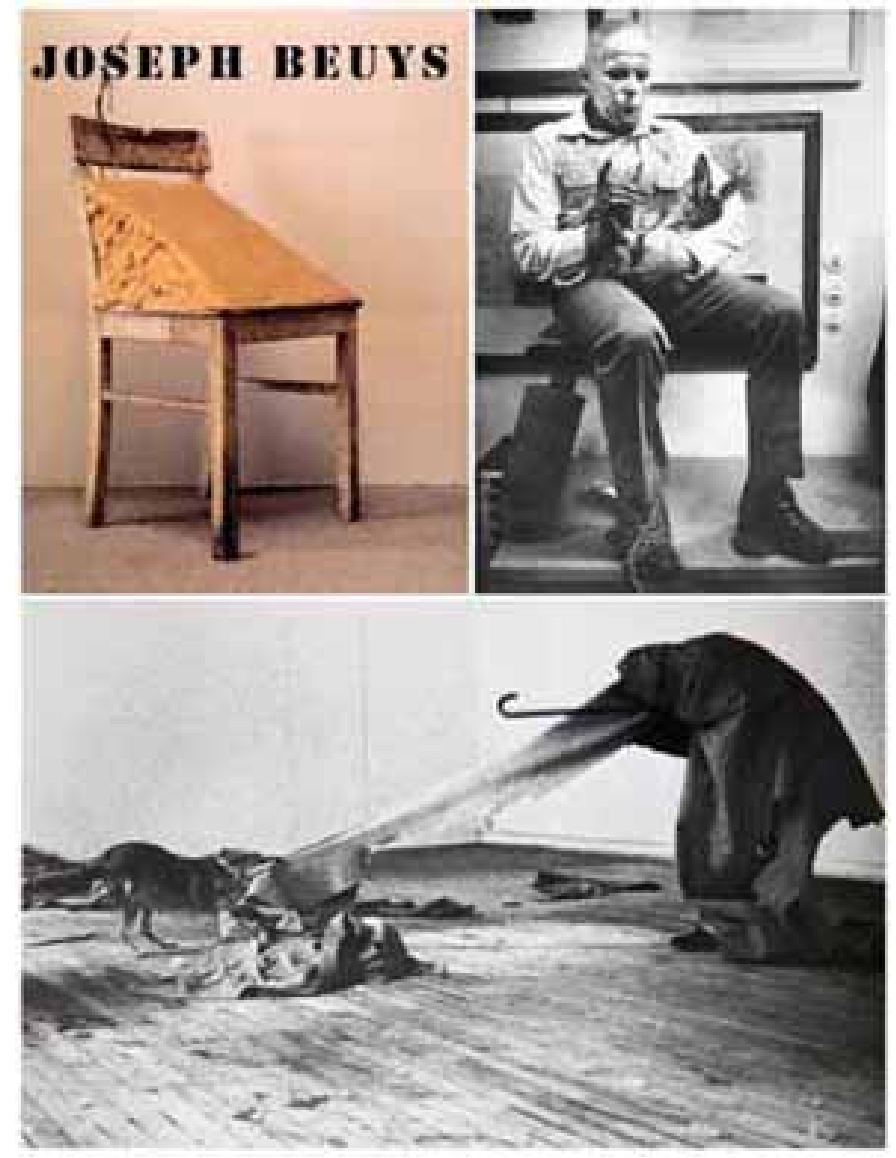

Fig. 2. The Works of Joseph Beuys

Concept of art of this period is to explore the application of the material period. It began as an artistic language of the material in-depth thinking, and this understanding is "natural": study limitations of the material that is external morphology, the carrier's performance may be only its color and shape, maybe just its texture or structure. Understanding of the material the externalization and naturalization, virtually the material in art with a simple prescriptive, the material that is at that time only as "art" language: a communication symbol material carrier, an artistic media forms exist. Materials of the "Nature" is not only the material to be "regulations" in the media and vector art form, this also makes the material 
"prescriptive" imperceptibly formed a tradition, in the history of art is "inherited" a very long time, some have even been "inherited" to this day.

In the British artist Henry Spencer Moore's (1898 - 1986) abstract sculpture, people saw in stone "man and nature isomorphic". Henry Moore's many works are used or borrowed from natural materials and styling, in his view, each material has its inner life, art is able to serve, and meanwhile, he has created using the material properties of common materials with chic styling, while the material to rise to an emotional level [4$6]$.

Artist conceptual understanding of the material, from the external morphology of the material inside the material implication steering, starting from its own physical attributes, so that the material itself saying force is discovery, excavation, and the will of publicity, thus, the material is just as artistic language material carrier, the concept is to carry forward its existence and expression [7]. Artistic language get freshmen in the material forces of nature itself and creativity to get the release and performance, however, this material is not for artistic language autonomy, although this art for artists and their artistic language occurred a decisive role, but the fact is considered to be subject to the artist, thought and will become the spokesman for the artist, art materials began as a carrier of artistic language exist, "The artist is an artist in the creation of the materials used to speak"!

\section{WALK IN THE INNER AND OUTER BOUNDARIES}

With the development of the process of human civilization, especially with the rise and development of industrial civilization, technological advances not only broadens the field of human knowledge of the material, also deepened in the art in the field of human understanding of the material - from the materials application technology and materials have gradually shifted the external form of the intrinsic cultural significance, this level of artistic language (material) in contemporary installation art was particularly prominent, different from the traditional fine arts shelves, such works of art will not do any kind applied directly to processing and reconstruction works of art which, Here, the material as a cultural symbol and meaning, its intrinsic meaning is the key artistic language[8-10].

Earth Artists believe art and life, art and nature should be no strict boundaries. With economic development, resources are severely depleted, people gradually realized that pollution and harm caused by excessive consumption, Earth artists trying to re-establish the relationship between man and nature, thus more attention to their relationship with nature. Before the Earth Art, such as pop art etc. Still praise industrial and manufactured goods, Earth Art is a kind of anti-industrial and anti-urban aesthetic tendencies, they began to consider the restoration of the environment, earth art began to play the role of ecological or social roles, as Heise's Double Negative (1969), Walter De Maria's Lightning Field (1977), Christo \& JeanneClaude's On the Way to The Gates (1972), Wrapped Reichstag (1995), as shown in Figure 3. Earth Art painting broke the traditional shackles of points and lines, also get rid of the traditional sculpture "body" stereotype and a single, meanwhile no means arbitrary and abrupt color art, it encompasses the fullness of the aesthetic elements of nature itself, with saturated colors of nature, forming majestic momentum, giving the mind a strong shock and sympathy $[11,12]$.
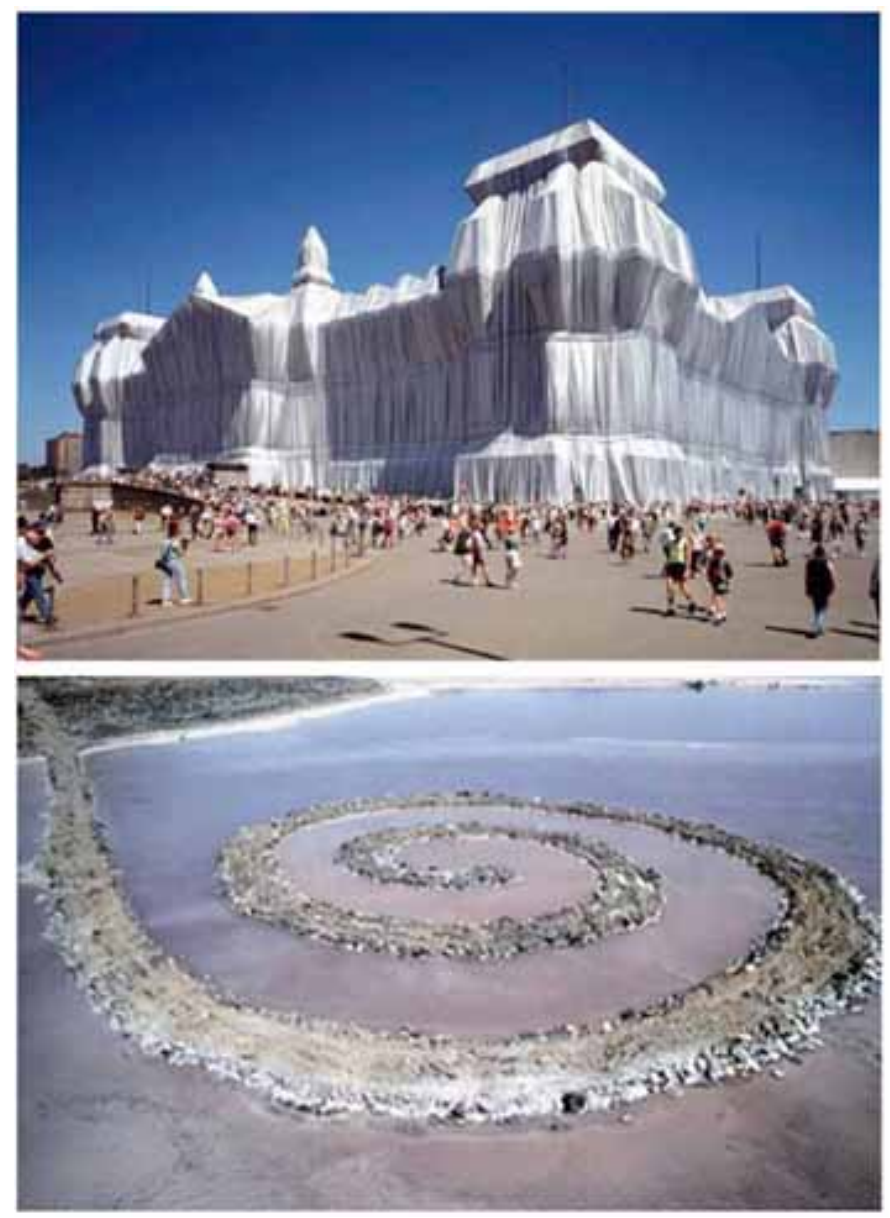

Fig. 3. The Works of Earth Artists

In modern art, material refers to the times and the significance is not only a physical presence in the environment, and its life in a complex society with a more complex social solidarity, and other things have a correlation can not be cleaned, therefore, the understanding of the material and not a single meaning referent, but has more meaning in nature, the same kind of materials, in different artistic context, will produce different artistic language, obtain a variety of interpretation, this is an artist artistic use of language material offers a myriad of possible, human discovery and creation of the material of the future and add a rich visual arts charm.

American artist Richard Tuttie that material is natural. For us, material expression language how to expand the concept of narrative, tools and techniques to promote the creation of the intensity of the performance, as well as how physical materials beyond the original artists in the hands of the cultural property, these are modern art education material application performance. If the development of modern art is the role of the visual form of development, postmodern art is will be "material" into omnipresent artistic life. 


\section{CONCLUSION}

With the gradual strengthening of human rational thinking, people on the natural, social and people's own deepening understanding and improving, new materials, new theories emerging, human gradual deepening understanding of the material, they promote human understanding of materials gradual deepening of this in-depth bring arts a strong impact, art "material" concept is constantly reinventing- in addition to the traditional sense of those arts materials, all the artists discovered and expressive and persuasive elements were involved in the field of art and become artistic material. In the contemporary art education, materials used to thinking imagination, explore new forms of artistic expression material, in the experiment, different properties of the material to try and exploration, from the initial discovery to the final form of the resulting artistic expression, from the initial discovery to the final the resulting artistic form of expression, artistic thoughts, ideas, themes, techniques, personalized, no center of artistic language concepts, are manifestations of art material's antitraditional, interest in life and modernization performance thoroughly.

In the contemporary art education, we should guide students to fully understand the comprehensive materials natural and social attributes, process on the plasticity and stochastic factors, it brings the charm of artistic language, raising materials possess rich potential of expression on aesthetic subject complicated, delicate feeling psychological aspects, continuous exploration and efforts, composite materials of modern art enriched and perfected on types and modalities performance, in order to achieve a perfect interpretation of art.

\section{ACKNOWLEDGMENT}

The authors gratefully thanks the financial support by Research Project in National Social Science Foundation Art
Project (14BG085), Jilin Social Science Fund Project (2013BS14); Youth fund of Northeast Normal University in philosophy and social science school projects (12QN017); Youth fund of Northeast Normal University in philosophy and social science school projects - Art project (MSZX2012-01). Corresponding author: Fan WANG, Wangf06@163.com, Professor, Northeast Normal University, CHINA. Hongtao Zhou, lifeisfurniture@gmail.com, Assistant professor, University of Hawai’i at Manoa, USA.

\section{REFERENCES}

[1] Herbert Edward Read, The Philosophy of Modern Art, Kessinger Publishing, 2007.

[2] Andy Warhol, The Philosophy of Andy Warhol, Penguin Classics, 2007.

[3] Jean Lahor, Art Nouveau, Sirrocco-Parkstone International, Penguin Classics, 2007.

[4] Henry Moore, Ann Garrould, Henry Moore: Complete Drawings, Lund Humphries Publishers Ltd, 1996.

[5] McClelland, David, The Drawings of Henry Moore, Library Journal, vol. 135, 2010, pp. 81-85.

[6] Anita Feldman, Ann Wagner, Henry Moore: Late Large Forms. Rizzoli, 2012.

[7] David Mitchinson, Celebrating Moore: Works from the Collection of The Henry Moore Foundation, Lund Humphries Publishers Ltd, 2006.

[8] Florence Muller, Fashion Game Book: A World History of 20th-century Fashion, Assouline, 2008.

[9] Bruno Munari, Design As Art, Penguin Global, 2009.

[10] Matthew Kieran, Contemporary Debates in Aesthetics and the Philosophy of Art, Blackwell Publishers, 2005.

[11] Ian Chilvers, John Glaves-Smith, A Dictionary of Modern and Contemporary Art, Oxford University Press, 2nd Revised edition, 2009.

[12] Clarke Angela, Hulbert Shane, Envisioning the Future: Working toward Sustainability in Fine Art Education, International Journal of Art \& Design Education, vol.35, 2005, pp.35-50. 